\title{
EFEITO DA ADIÇÃO DE $\beta$-CICLODEXTRINA NO PREPARO E ARMAZENAMENTO DA BEBIDA DE CHÁ VERDE
}

\author{
T. B. $\operatorname{SISTI}^{1}$, G. M. ZANIN ${ }^{2}$, F.F. MORAES ${ }^{2}$, R. G. GOMES ${ }^{1}$; R. C. BERGAMASCO ${ }^{1}$ \\ ${ }^{1}$ Universidade Estadual de Maringá, Departamento de Engenharia de Alimentos \\ ${ }^{2}$ Universidade Estadual de Maringá, Departamento de Engenharia Química \\ e-mail para contato: rcbergamasco@uem.br
}

\begin{abstract}
RESUMO - O chá verde tem sido muito estudado devido às suas características funcionais e grande quantidade de compostos polifenólicos presentes naturalmente. Por seus benefícios, indústrias estão produzindo o chá pronto para consumo em grande escala, visando a praticidade. Porém, a alta temperatura durante o processamento não preserva seus compostos e a perda de suas características saudáveis é alta. O objetivo deste trabalho foi avaliar o efeito da adição de ßciclodextrina ( $(-\mathrm{CD})$ no preparo e estabilidade de armazenamento da bebida de chá verde. Os resultados obtidos demonstraram que na bebida preparada com sachê comercial, a ß-CD atuou na preservação de compostos fenólicos totais. Porém, durante o armazenamento da bebida por 30 dias à temperatura ambiente, a adição de ß-CD na bebida não contribuiu para a preservação dos polifenóis totais do chá. $\mathrm{Na}$ análise sensorial do produto, com adição de $1 \%$ de $B-C D$, observou-se que a ciclodextrina também contribuiu para a redução do amargor do chá.
\end{abstract}

\section{INTRODUÇÃO}

Com o crescimento do consumo de chá verde no mundo inteiro, deu-se atenção ao chamado chá verde brasileiro, obtido a partir das folhas de Camellia sinensis var. assamica (Saito, 2007). Camellia sinensis é um arbusto de pequeno porte pertencente à família Theaceae (Saigg e Silva, 2009).

As folhas de Camellia sinensis são usadas na fabricação de mais de um tipo de chá, sendo estes classificados em três categorias: o que passa por um processo de fermentação (preto), o que não é fermentado (verde) e o que sofre uma fermentação parcial (oolong). No mundo, são produzidas anualmente cerca de três bilhões de toneladas de chá, sendo $20 \%$ somente de chá verde. Os três tipos juntos constituem a segunda bebida não-alcoólica mais consumida no mundo (Jacques et al., 2010; Lima et al., 2009).

Antes utilizado como medicamento, diversos estudos têm mostrado a importância do chá verde e desses compostos, que estão diretamente ligados com a atividade fisiológica, a habilidade de capturar espécies reativas de oxigênio, quelar íons metálicos, inibir a nitrosação e serem antioxidantes naturais (Port's, 2011; Saigg e Silva, 2009). 


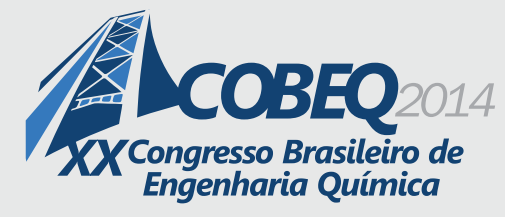

As folhas não fermentadas de C. sinensis contêm cerca de $15-25 \%$ de proteínas, $5 \%$ de glicídeos, 30\% de polifenóis, 1-5\% de alcalóides, vitaminas: C, B1, B2 e K e minerais como flúor (130-160 mg/kg), potássio, magnésio, cálcio, ferro, manganês e fósforo, entre outros (Saito, 2007).

A composição nutricional desse produto, principalmente por compostos bioativos, como os polifenóis, fazem dele um alimento funcional, que pode trazer benefícios à saúde (Matsubara et al., 2006; Saigg e Silva, 2009). Os compostos fenólicos podem ser classificados em categorias, sendo flavonóides uma de suas maiores. O chá verde é caracterizado pelo seu alto conteúdo de flavonóides, principalmente catequinas (Kodama et al., 2010).

As catequinas são sintetizadas nas folhas. Quanto mais jovem a folha, maior a quantidade de catequina presente, chegando a constituir cerca de 30\% do seu peso seco. São compostos incolores e solúveis em água responsáveis pelo amargor e adstringência das folhas da $C$. sinensis (Lima et al., 2009; Camargo, 2011).

Em trabalho realizado por Jacques et al. (2010), o conteúdo de catequina presente no chá verde foi de $10,185 \mathrm{mg} / \mathrm{g}$ de folha seca. Já em um estudo de Labbé et al. (2008) encontrou-se valores de 853,8 e $969,3 \mu \mathrm{g} / \mathrm{mL}$ de catequinas presentes no chá verde de três diferentes marcas japonesas. E, segundo Dalluge e Nelson (2000), o conteúdo de catequinas presente no chá verde preparado pela infusão é cerca de $60 \mathrm{mg} / \mathrm{g}$, variando entre 9 e $117 \mathrm{mg} / \mathrm{g}$. Em outro estudo, Morais-de-Souza et al. (2011), encontraram valores entre 57,6 e 104,17 mg EACG.g ${ }^{-1}$ de amostra. E, com um método que envolvia agitação e erva a granel, Nishiyama et al. (2010) alcançaram valores de compostos fenólicos totais de, aproximadamente, $125 \mathrm{mg} \cdot \mathrm{g}^{-1}$ de erva.

Um estudo realizado por Chen et al. (2001), demonstra que a concentração das catequinas do chá verde é bem menor em bebidas enlatadas e engarrafadas do que no chá tradicionalmente preparado pela infusão. Isto mostra que, apesar de todos os benefícios, as catequinas não são estáveis, já que essas bebidas prontas para o consumo passam por outros processos, como o aquecimento a altas temperaturas. A praticidade é uma das melhores qualidades desse tipo de bebidas, já que são fáceis de armazenar e possuem longa durabilidade. Porém, algumas deixam a desejar quando o assunto é saúde. Muitas bebidas perdem suas características, tanto sensoriais quanto nutricionais quando passam pelo processamento fazendo com que seu consumo seja limitado somente pela praticidade.

Kim et al. (2007) observaram que a concentração do total de catequinas no chá verde diminui após um tratamento térmico de esterilização, processo realizado na manufatura de chás comerciais prontos para consumo. Constatou-se também que elas são vulneráveis à degradação e isomerização durante o processamento térmico e armazenamento. A epimerização das catequinas, que ocorre durante o aquecimento a altas temperaturas é alterada de acordo com as condições de aquecimento, mas gerará, certamente, alterações na composição, tanto qualitativa quanto quantitativa destes compostos. Aproximadamente $50 \%$ das catequinas do chá verde são epimerizadas por tratamento térmico, ou seja, cerca de metade das propriedades benéficas do chá verde são perdidas nas bebidas prontas para consumo (Bazinet et al., 2010; Chen et al., 2001). 


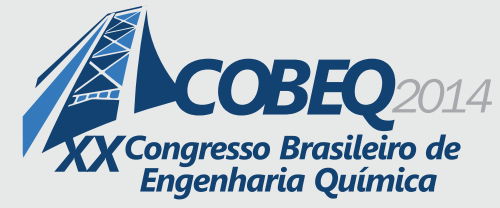

Em vista disso, uma forma de minimizar essas perdas, é a encapsulação, que consiste em aprisionar partículas (sólidas, líquidas ou gasosas) em cápsulas (filme fino ou camada polimérica) ou moléculas (ciclodextrinas), protegendo-as do ambiente externo, como luz, calor, umidade (Matioli e Rodriguez-Amaya, 2003).

Várias técnicas e agentes encapsulantes vêm sendo estudados, dentre eles a encapsulação por inclusão molecular em ciclodextrinas. De acordo com Matioli e Rodriguez-Amaya (2003), as ciclodextrinas são substâncias obtidas a partir do amido, com formato de um cone truncado, cujo interior apresenta caráter hidrófobo, enquanto a sua superfície externa é hidrófila. Esta estrutura faz dela uma "molécula hospedeira", possibilitando a formação de complexos de inclusão com várias "moléculas hóspedes" de polaridade reduzida.

Em vista disso, o presente trabalho propõe avaliar o efeito da adição de $\beta$-ciclodextrina tanto no preparo, envolvendo altas temperaturas, quanto na estabilidade de armazenamento da bebida. Como a ciclodextrina atua como agente encapsulantes de uma série de compostos, a sua adição na bebida de chá verde pode alterar o sabor da bebida, ou seja, a ciclodextrina pode atuar no mascaramento do sabor indesejável da bebida, reduzindo o seu amargor. Portanto, uma análise sensorial foi realizada na bebida com o objetivo de observar este comportamento.

\section{MATERIAIS E MÉTODOS}

\subsection{Amostra}

O chá verde comercial, na forma de sachê, utilizado neste estudo, foi adquirido no comércio local de Maringá-PR.

\subsection{Preparo do Chá}

O processo de infusão foi realizado conforme descrito no trabalho de Bazinet et al. (2010), com algumas modificações. Sachês de chá verde foram abertos e o seu conteúdo acondicionado em um recipiente. Em seguida, adicionou-se água a $80^{\circ} \mathrm{C}$ e $\beta$-ciclodextrina $(0,5 \%$ e $1 \%-\mathrm{m} / \mathrm{v})$. Esta mistura foi agitada levemente por 10 minutos, para garantir uma melhor extração dos compostos fenólicos (Nishiyama et al., 2010).

Após o tempo de infusão, o chá foi filtrado, descartando as folhas. $\mathrm{O} \mathrm{pH}$ foi reduzido com suco de limão concentrado ( $\mathrm{pH} 4$ ), para eliminar a possibilidade de crescimento de microorganismos durante o armazenamento do chá.

$\mathrm{O}$ líquido foi acondicionado em garrafas de vidro, seguindo para a pasteurização, à $85^{\circ} \mathrm{C}$, por 20 minutos. O produto foi armazenado à temperatura ambiente durante 30 dias. Uma bebida de chá verde foi preparada sem a adição de $\beta$-ciclodextrina, para efeito de comparação. 


\subsection{Determinação dos Compostos Fenólicos Totais}

Em tempos estabelecidos de 0, 10, 20 e 30 dias, alíquotas foram coletadas das amostras para a quantificação de compostos fenólicos a partir do método de Folin-Ciocalteau. Os resultados dos teores de compostos fenólicos totais foram expressos como equivalentes de catequina (mg ECAT/g), pois esse é o composto de maior concentração nas folhas de Camellia sinensis.

\subsection{Análise Sensorial}

A análise sensorial foi realizada em escala laboratorial com 40 provadores não treinados. As amostras foram distribuídas em copos plásticos codificados com números aleatórios de 3 dígitos. As avaliações foram realizadas em cabines individuais.

Foi realizado um teste de comparação e avaliou-se sensorialmente o atributo amargor de duas amostras de chá, uma amostra padrão sem adição de $\beta$-ciclodextrina e outra contendo $1 \%$ da mesma, preparadas no dia da análise. Os provadores deveriam optar pela amostra mais intensa no amargor.

\subsection{Análise Estatística}

Todas as determinações foram efetuadas em triplicatas, e os resultados obtidos foram submetidos a análise de variância e teste de Tukey, ao nível de 5\% de probabilidade, usando o programa STATISTICA 7.0.

\section{RESULTADOS E DISCUSSÃO}

Na Tabela 1 são apresentados as concentrações de compostos fenólicos totais, em mg de catequina/g de erva, presentes nas bebidas de chá verde com e sem adição de $\beta$-CD.

Tabela 1 - Média das concentrações das diferentes formas de obtenção do chá à temperatura ambiente.

\begin{tabular}{c|c}
\hline Bebida de chá verde & Concentração de compostos fenólicos (mg ECAT/g de erva) \\
\hline Controle & $143,98^{\mathrm{a}} \pm 2,56$ \\
Adição de $0,5 \%$ de $\beta$-CD & $147,4^{\mathrm{a}} \pm 5,84$ \\
Adição de $1 \%$ de $\beta$-CD & $164,43^{\mathrm{b}} \pm 3,90$
\end{tabular}

Médias seguidas de mesma letra na coluna não diferem entre si estatisticamente, ao nível de significância de 5\%.

De acordo com os dados apresentados na Tabela 1 verifica-se que o teor de catequina presente no chá é maior do que os apresentados na literatura (Jacques et al., 2010; Labbé et al., 2008; Dalluge e Nelson, 2000; Morais-de-Souza et al., 2011; Nishiyama et al., 2010). Saito (2007) relata que a quantidade de compostos fenólicos presentes no chá verde brasileiro é maior 


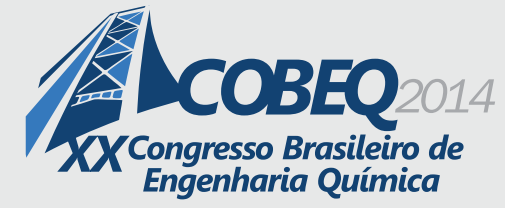

Engenharia Química
19 a 22 de outubro de 2014

Florianópolis/SC

quando comparado com os chás de outros países, devido às características de clima e solo. Além disso, o teor de compostos fenólicos no chá verde também pode estar relacionado com a forma de preparo do chá. Zimmermann e Gleichenhagen (2011) registraram um aumento de $20 \%$ no conteúdo de catequina durante o processo de infusão do chá verde, usando suco de limão antes da infusão. Eles sugerem que para obter uma quantidade máxima de catequina, durante o processo de infusão do chá, é necessário usar água em ebulição e adicionar ingredientes para reduzir o pH.

Com relação ao efeito da adição de $\beta$-CD no preparo do chá verde, observa-se que houve um aumento estatisticamente significativo $(\mathrm{p}<0,05)$ no teor de catequina no chá preparado com $1 \%$ de $\beta$-CD, quando comparado ao chá preparado sem a ciclodextrina. Porém, o uso de $0,5 \%$ de $\beta$-CD não afetou significativamente a concentração de compostos fenólicos totais do chá. Neste caso, a $\beta$-CD atuou na proteção da catequina durante o preparo do chá, porém em concentrações maiores, de $1 \%$.

Quando avaliou-se a estabilidade dos compostos fenólicos nas amostras de chá verde armazenado a temperatura ambiente (Figura 1), pode-se constatar que durante 10 dias de armazenamento houve uma preservação dos compostos tanto na bebida controle quanto na bebida preparada com $\beta$-CD. Este fenômeno pode estar relacionado com a adição do suco de limão. Bazinet et al. (2010) demonstraram que a estabilidade das catequinas no chá verde durante a estocagem é maior sob condições ácidas $(\mathrm{pH} 4)$ e baixas temperaturas $\left(4^{\circ} \mathrm{C}\right)$. Os autores também destacam a vantagem do $\mathrm{pH}$ baixo de preservar o produto contra a ação de micro-organismos patogênicos, que poderiam alterar a qualidade do chá durante a estocagem.

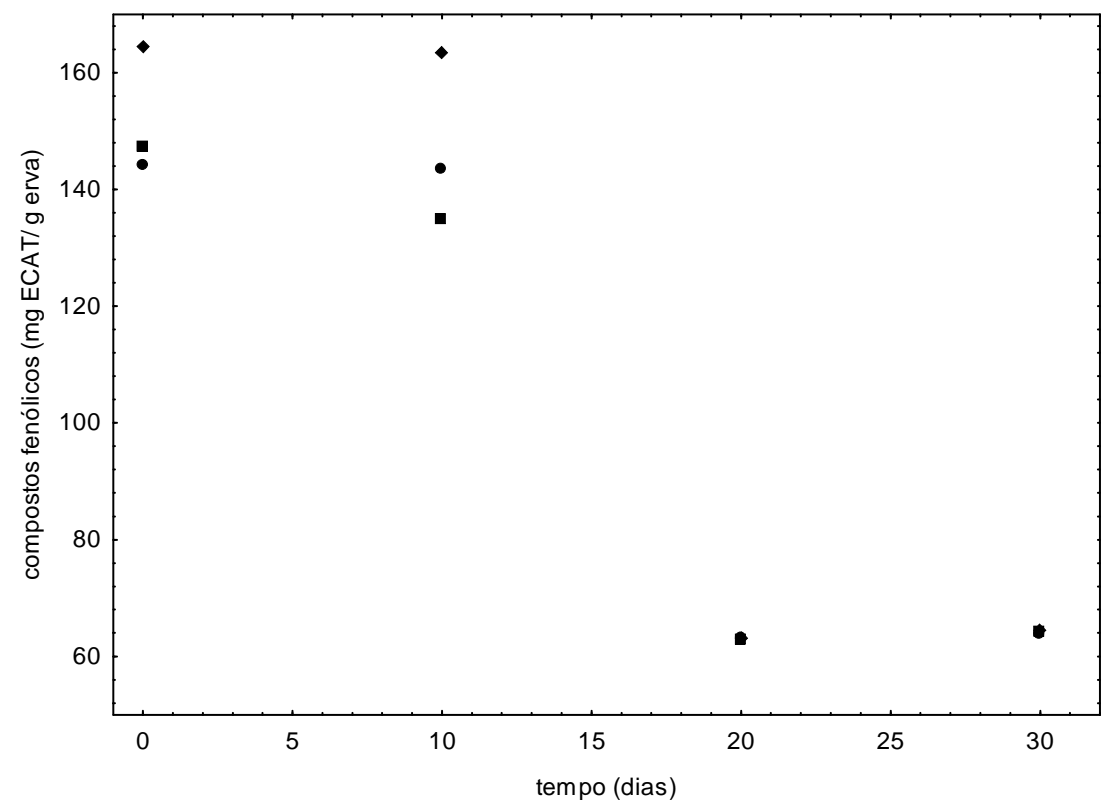

Figura 1 - Concentração de compostos fenólicos na bebida de chá na amostra controle $(\bullet)$, com $0,5 \%$ de $\beta$-CD ( $)$ e com $1 \%$ de $\beta-C D(\bullet)$. 


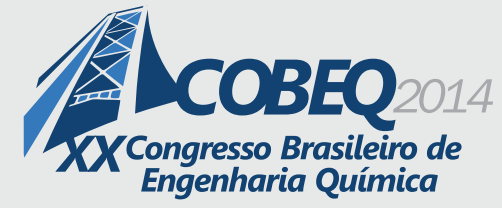

Contudo, um resultado inesperado foi observado em todas as amostras após 20 dias de armazenamento (Figura 1); houve uma redução no conteúdo de compostos fenólicos no chá em mais de 50\%. Ou seja, a adição de $\beta$-CD no chá verde não contribuiu para a preservação dos compostos fenólicos durante o armazenamento. Cano (2011) avaliou a estabilidade do complexo de inclusão catequina: $\beta$-CD em solução aquosa, armazenado a $20^{\circ} \mathrm{C}$ por 90 dias. Neste trabalho o autor observou que após 40 dias de estocagem a catequina livre em solução havia oxidado, enquanto na forma de complexo de inclusão tinha-se, ainda, $50 \%$ de catequina remanescente. Ele concluiu que a $\beta$-CD retardou a oxidação do composto, mas não contribuiu para a preservação total.

A análise sensorial das amostras de chá verde foi realizada com provadores não treinados, os quais deveriam avaliar duas amostras de chá verde e escolher qual delas possuía o atributo amargor mais intenso. Foram preparadas amostras de chá verde controle e com adição de $1 \%$ de $\beta-C D$.

Segundo a NBR 13088, que estabelece os valores mínimos de julgamentos corretos, verificou-se que para 40 provadores, 30 deveriam apontar para a amostra mais amarga, que esperava ser o chá sem adição de $\beta$-CD, para que houvesse $99,9 \%$ de confiança nos resultados. Dos 40 provadores, $85 \%$ optaram pela amostra controle, isto é, 34 escolheram a amostra que não continha $\beta$-ciclodextrina, como a mais amarga. Este resultado demonstra que a $\beta$-CD foi eficaz também no mascaramento do sabor amargo do chá verde. De acordo com Nishiyama et al. (2010), o sabor amargo é resultado da liberação de taninos presentes no chá, portanto, a ßciclodextrina mostrou-se eficiente na encapsulação destes compostos, reduzindo o seu efeito adstringente.

\section{CONCLUSÃO}

A partir desse estudo, pode-se concluir que a ß-ciclodextrina, na concentração de $1 \%$, foi satisfatória na encapsulação dos compostos fenólicos do chá verde, atuando na preservação destes durante o preparo do chá e no mascaramento do sabor amargo da bebida. Durante 20 dias de armazenamento, a temperatura ambiente, constatou-se uma degradação de mais de $50 \%$ dos compostos fenólicos no chá, até mesmo para a amostra contendo $\beta$-ciclodextrina. Isto demonstra que a $\beta$-ciclodextrina não foi eficaz na estabilidade de armazenamento dos compostos fenólicos do chá. Portanto, conclui-se que a presença de $\beta-C D$ no chá verde contribuiu para a preservação dos seus compostos ativos durante o processamento da bebida, e atuou na redução do sabor amargo do mesmo, deixando-o mais agradável sensorialmente.

\section{REFERÊNCIAS}

BAZINET, L.; ARAYA-FARIAS, M.; DOYEN, A.; TRUDEL D.; TÊTU, B,; Effect of process unit operations and long-term storage on catechin contentes in EGCG-enriched tea drink. Food Research International, 43, p. 1692-1701, 2010. 


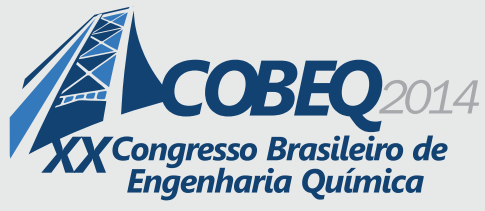

19 a 22 de outubro de 2014

Florianópolis/SC

CAMARGO, L. E. A.; Avaliação das atividades antioxidante e antifúngica da Camellia sinensis (L.) Kuntze obtida por diferentes formas de produção. Dissertação (Mestrado em Ciências Farmacêuticas) - Concentração de Ciências da Saúde, Universidade Estadual do CentroOeste. Guarapuava, 2011.

CANO, C. F. Estudio de inclusión de derivados de catequina em ciclodextrina: actividad antioxidante y estabilidad. Tese (Doutorado em Química), Facultad de Ciencias Químicas y Farmacêuticas, Universidad de Chile. Santiago, Chile, 2011.

CHEN, Z.; Degradation of Green Tea Catechins in Tea Drinks. Journal of Agricultural and Food Chemistry, 49, p. 477-482, 2001.

DALLUGE, J. J.; NELSON, B. C.; Determination of tea catechins. Journal of Chromatography A, 881, p. 411-424, 2000.

JACQUES, A. C.; Conteúdo de (-)catequina em chás comerciais (Camellia sinensis): preto e verde. In: XIX CONGRESSO DE INICIAÇÃO CIENTÍFICA. Anais eletrônicos. Pelotas: UFPel. 2010. Disponível em: < http://www.ufpel.edu.br/cic/2010/cd/ca.htm> Acesso em: 02 mar. 2013.

KIM, E. S., LIANG, Y. R., JIN, J., SUN, Q. S., LU, J. L., DU, Y. Y.; Impact of heating on chemical compositions of green tea liquor. Food Chemistry, 103, p. 1263-1267, 2007.

KODAMA, D. H.; GONÇALVES, A. E. S. S.; LAJOLO, F. M.; GENOVESE, M. I.; Flavonoids, total phenolics and antioxidante capacity: comparison between comercial green tea preparations. Ciência e Tecnologia de Alimentos, Campinas, 30(4), p. 1077-1082, out.-dez. 2010.

LABBÉ, D.; TÊTU, B.; TRUDEL, D.; BAZINET, L.; Catechin stability of EGC- and EGCGenriched tea drinks produced by a two-step extraction procedure. Food Chemistry, 111, p. 139-143, 2008.

LIMA, J. D.; MAZZAFERA, P.; MORAES, W. S.; SILVA, R. B.; Chá: aspectos relacionados à qualidade e perspectivas. Ciência Rural, Santa Maria, 39(4), p. 1270-1278, jul, 2009.

MATIOLI, G.; RODRIGUEZ-AMAYA, D. B.; Microencapsulação do licopeno com ciclodextrina. Ciência e Tecnologia de Alimentos, 23, p. 102-105, dez. 2003.

MATSUBARA, S.; RODRIGUEZ-AMAYA, D. B.; Teores de catequinas e teaflavinas em chás comercializados no Brasil. Ciência e Tecnologia de Alimentos, 26, p. 401-407, abr.-jun. 2006.

MORAIS-DE-SOUZA, R. A., Potencial antioxidante e composição fenólica de infusões de ervas consumidas no Brasil. Dissertação de mestrado em Ciência, Área de Concentração Ciência e Tecnologia de Alimentos, Universidade de São Paulo - Escola Superior de Agricultura Luiz de Queiroz, 2007.

NBR 13088 - Teste de comparação pareada em análise sensorial dos alimentos e bebidas. 1994. $7 \mathrm{p}$.

NISHIYAMA, M. F.; COSTA, M. A. F.; COSTA, A. M.; SOUZA, C. G. M.; BOER, C. G.; BRACHT, C. K.; PERALTA, R. M.; Chá verde brasileiro (Camellia sinensis var assamica): efeitos do tempo de infusão, acondicionamento da erva e forma de preparo sobre a eficiência de extração dos bioativos e sobre a estabilidade da bebida. Ciência $e$ Tecnologia de Alimentos, 30, p. 191-196, maio, 2010. 
PORT'S, P. S.; Compostos fenólicos e potencial antioxidante de ervas consumidas na região amazônica brasileira. Dissertação (Mestrado em Ciência de Alimentos) - Faculdade de Engenharia de Alimentos, Universidade Estadual de Campinas. Campinas, 2011.

SAIGG, N. L.; SILVA, M. C.; Efeitos da utilização do chá verde na saúde humana. Ciências da Saúde, 7(1), p. 69-89, 2009.

SAITO, S. T.; Estudo químico e avaliação da atividade antioxidante de chá verde brasileiro (Camellia sinensis var. assamica) Cultivar IAC-259. 2007. Dissertação (Mestrado em Ciências Farmacêuticas) - Universidade Federal do Rio Grande do Sul. Porto Alegre, 2007.

ZIMMERMANN, B. F.; GLEICHENHAGEN, M.. The effect of ascorbic acid, citric acid and low pH on the extraction of green tea: How to get most out of it. Food chemistry 124(4) ,p. 1543-1548, 2011. 